\title{
VERTICALIDADES E HORIZONTALIDADES NA CERTIFICAÇÃO DA PRODUÇÃO DE CACAU ORGÂNICO NO SUL DA BAHIA
}

\section{VERTICALITIES AND HORIZONTALITIES IN THE CERTIFICATION OF ORGANIC COCOA PRODUCTION IN THE SOUTH OF BAHIA}

\author{
Laís Boto Xavier \\ Universidade Federal Rural do Rio de Janeiro, Instituto Multidisciplinar, Pós-Graduação em Geografia, \\ Nova Iguaçu, RJ, Brasil \\ laisbotoxavier@live.com
}

Francisco das Chagas do Nascimento Jr. Universidade Federal Rural do Rio de Janeiro, Instituto Multidisciplinar, Departamento de Geografia, Nova Iguaçu, RJ, Brasil fcnascimentojr@gmail.com

Jorge Chiapetti Universidade Estadual de Santa Cruz, Departamento de Ciências Agrárias e Ambientais, Ilhéus, BA, Brasil chiapeti@uesc.br

\section{Resumo}

O presente trabalho trata das novas dinâmicas de especialização da produção de cacau no Sul do estado da Bahia. Desde a chamada "crise do cacau", pôde-se observar a disseminação de novas formas de produção de amêndoas na região, dentre as quais se destaca a produção de cacau orgânico certificado. Tal modelo de produção alinha-se ao fenômeno de descomoditização da produção agrícola, o qual possui como característica a valorização de formas específicas de produção local, o fortalecimento da identidade dos produtores e, no caso do Sul Baiano, se estabeleceu como estratégia para superar a crise vivenciada pela região desde o final da década de 1980. Através de pesquisa empírica, avaliou-se as atividades desenvolvidas pela Cooperativa Cabruca e pela Rede Povos da Mata, organizações que atuam no apoio à produção de cacau orgânico certificado no Sul Baiano. O intuito de analisar aquelas diferentes organizações, foi averiguar em que medida a adoção de modelos distintos de certificação da produção orgânica (a certificação por auditoria e a certificação participativa) possibilita aos agricultores alcançarem maior autonomia econômica e, a região, tornar-se menos subordinada ao mercado de commodities. Finalmente, concluiu-se que apesar dos obstáculos existentes para pequenos e médios produtores obterem a certificação, a construção de articulações locais permitem aos mesmos se inserirem, paulatinamente, nos circuitos espaciais de produtos certificados.

Palavras-chave: Especialização regional. Descomoditização. Cacau orgânico. Cooperativa Cabruca. Rede Povos da Mata. 


\section{Abstract}

The present research deals with the new dynamics of regional specialization of cocoa production in the southern state of Bahia. Since the so-called "cocoa crisis", it has been possible to observe the spread of new forms of cocoa production in the region, among which stands out the production of certified organic cocoa. This form of production is aligned with the phenomenon known as de-commoditisation of agricultural production, a process that brings as a characteristic the valorization of the specific forms of local production, the pursuit for the construction of a greater autonomy and identity of the producers and, in the case of the south of Bahia, established since the 1980 as a strategy to overcome the crisis experienced by the region. Through the presentation of the experiences of the Cabruca Cooperative and the Rede Povos da Mata, we sought to analyze two different types of certification of organic cocoa production in southern Bahia, certification by auditing and participatory certification. Our intention with the analysis of these different experiences was to evaluate to what extent the adoption of different models of control of certified production can allow the producer and the region to obtain a greater autonomy (political and economic), to become less subordinated to the market conventional agricultural commodities and to promote more equal regional development.

Keywords: Specialization regional. Organic cocoa. De-commoditisation. Cabruca Cooperative. Rede Povos da Mata.

\section{Introdução}

O presente trabalho aborda as transformações recentes do mercado de commodities agrícolas, através da análise de iniciativas de diferenciação e certificação da produção no campo. Em especial, busca compreender as mudanças ocorridas na cacauicultura brasileira, com destaque para a emergência da produção de cacau orgânico certificado numa das principais regiões produtoras deste gênero agrícola no país - o Sul do estado da Bahia.

Tal modelo de produção agrícola - a produção orgânica certificada - vem sendo praticada como forma de valorizar manejos e práticas agrícolas que difundam os princípios do chamado desenvolvimento sustentável, fomentem relações de produção mais justas no campo, bem como fortaleçam aspectos socioculturais próprios das regiões produtoras. Os selos de certificação tornaram-se também uma ferramenta utilizada para agregar valor aos produtos e, atualmente, vem alcançando os mais variados gêneros agropecuários, dentre os quais, destacam-se: o café, o vinho, o queijo, as frutas tropicais, entre outros. No caso da produção de cacau esse fenômeno também se faz presente e, aparentemente, vem implicando numa relativa "atualização produtiva" do Sul Baiano, 
região que, apesar da crise vivenciada desde o final dos anos 1980, se constitui, ainda hoje, num dos principais centros cacauicultores do Brasil.

A busca dos produtores por se desvincular dos mercados agrícolas padronizados e consolidar novos nichos de mercados, tem como objetivo tornar agricultores e regiões produtoras menos vulneráveis às oscilações do mercado e aos baixos preços pagos pelas commodities, assim como torná-los menos subordinados às políticas das grandes corporações que comandam o agronegócio mundial (COGUETO, 2014; FREDERICO, 2013). Em contrapartida, tais estratégias almejam possibilitar aos produtores uma maior autonomia política e econômica através da redução do número de intermediários ao longo da cadeia de trocas; o aumento dos valores pagos ao agricultor pela sua produção; e o fortalecimento da identidade dos agricultores e das regiões produtoras (COGUETO, 2014; FREDERICO, 2013).

Diante da dinamicidade e complexidade desse movimento, denominado por alguns autores de "descomoditização" da produção agrícola (DAVIRON; VAGNERON, 2011), pretende-se avaliar como vem ocorrendo o novo processo de especialização regional da produção de cacau no Sul da Bahia, e analisar até que ponto a adoção destas estratégias de diferenciação, valorização e certificação da produção local está contribuindo para a construção de uma maior independência dos produtores e da região frente ao mercado convencional de cacau commodity.

Desse modo, face ao tema e aos propósitos da pesquisa, o presente trabalho foi organizado em três secções, além da introdução e das considerações finais. Na primeira parte, buscou-se compreender a emergência do fenômeno de certificação da produção agrícola e, sobretudo, refletir sobre seu significado para os lugares e regiões produtoras. Em seguida, voltando-se especialmente para o Sul da Bahia, avaliou-se o contexto de implantação dos sistemas de produção de cacau orgânico certificado, assim como se buscou reconhecer a escala e a representatividade atual desse novo tipo de produção na tradicional região cacaueira brasileira.

Por fim, com o propósito de avaliar diferentes experiências de certificação da produção de cacau orgânico na região e, adotando-se como procedimento de investigação o levantamento sistemático de dados secundários e a realização de pesquisas de campo 
(entrevistas e visitas técnicas à instituições, empresas e agricultores ${ }^{1}$ ), empreendeu-se uma análise das atividades desenvolvidas pela Cooperativa dos Produtores Orgânicos do Sul da Bahia (Cooperativa Cabruca) e a Associação Povos da Mata Atlântica do Sul da Bahia (Rede Povos da Mata). A escolha destas organizações se justificou na medida em que juntas, elas representam cerca de $80 \%$ do total de estabelecimentos formalmente reconhecidos como produtores de cacau orgânico certificado no Sul da Bahia (MAPA, 2020).

Através da descrição das atividades realizadas pela Cooperativa Cabruca e pela Rede Povos da Mata, cada qual apoiada em um modelo específico de certificação - a primeira baseada na certificação por auditoria e a segunda na certificação participativa examinou-se os benefícios para os produtores proporcionados por aqueles distintos tipos de reconhecimento e controle da produção no campo. Em suma, o propósito foi avaliar até que ponto as certificações se constituem em instrumentos capazes de proporcionar maior autonomia econômica e política para os agricultores, assim como averiguar em que medida as certificações se constituem em mecanismos capazes de fomentar um desenvolvimento regional mais amplo e igualitário.

\section{Considerações preliminares sobre as certificações e seu sentido (ambíguo) para os} lugares

O fenômeno recente de certificação das produções agrícolas pode ser caracterizado como um processo que, até certo ponto, busca se contrapor ao mercado agrícola convencional, tão caracterizado pela realização da produção em grande escala, pela difusão mundial de formas de consumo padronizadas, e pelo forte controle dos mercados exercido pelas grandes corporações do agronegócio. Conforme esclarece Frederico (2013),

[...] a lógica das commodities submete os agentes próprios do lugar ou região - produtores, transportadores, comerciantes e empresas locais aos desígnios dos agentes que atuam em rede na escala mundial grandes firmas exportadoras e importadoras (tradings), conglomerados

\footnotetext{
${ }^{1}$ As entrevistas ocorreram entre os dias 24 e 28 de julho de 2017, durante pesquisa de campo realizada no município de Ilhéus, Bahia. Ressalta-se que os nomes empregados para identificar os entrevistados são fictícios, tendo por objetivo preservar a identidade dos mesmos. Além disso, destaca-se que as informações primárias apresentadas contaram com o consentimento dos entrevistados.
} 
alimentícios e especuladores financeiros -, acarretando numa vulnerabilidade produtiva local (FREDERICO, 2013, p. 98).

Sob certo ponto de vista, o fenômeno de certificação da produção no campo pode ser compreendido como uma forma de reação de agricultores, consumidores, movimentos sociais e algumas instituições à lógica subalternizante dos lugares produzida pelos mercados de commodities agrícolas, os quais são frequentemente responsáveis por enfraquecer a identidade dos produtores agrícolas e submeter as regiões produtoras a comandos externos e a interesses essencialmente corporativos.

O movimento de valorização e certificação de formas específicas de produção local, constitui-se num fenômeno que abrange atualmente diversos produtos agropecuários, podendo-se citar como exemplos, no Brasil, as produções de vinhos na Serra Gaúcha (NIEDERLE; DELPHINE, 2010), cafés no Sul de Minas Gerais (COGUETO, 2014; FREDERICO; BARONE, 2015), queijos na Serra da Canastra (CRUZ; HESPANHOL, 2018); frutas tropicais no Médio Vale do São Francisco (REIS, 2015), além de cacau no Sul da Bahia.

De maneira geral, a diferenciação e a certificação da produção pode envolver diferentes aspectos da produção local, tais como: a indicação de procedência ou a denominação de origem do produto (Indicação Geográfica); a comprovação da realização de formas de comércio justo (Fair Trade); a realização da produção através de técnicas ecologicamente sustentáveis (orgânico, biodinâmico, Rainforest); e a produção de bens agrícolas de qualidade superior (produtos finos, gourmet) (COGUETO, 2014; FREDERICO; BARONE, 2015).

De acordo com Daviron e Vagneron (2011), a produção e a comercialização através de certificações tende a conferir uma maior independência aos produtores, pois valoriza as formas de produção próprias dos lugares (sua tradição, seu saber-fazer) e, especialmente no caso das produções ecologicamente "corretas" e "socialmente justas", busca estimular uma certa "conscientização ambiental e social"; feitos estes frequentemente negligenciados pela grande produção agrícola e pelo mercado convencional de produtos padronizados.

Ainda, a partir do momento em que o produtor adere ao modelo de certificação da produção agrícola, este, comumente, alcança uma maior valorização da sua produção, passando a vender seus produtos a preços acima daqueles praticados no mercado de 
produtos padronizados, tipo commodity (DAVIRON; VAGNERON, 2011). Por outro lado, para os consumidores, as certificações fornecem uma garantia legalmente comprovada do modelo agrícola e das relações sociais que fundamentaram a realização dos produtos consumidos. Neste sentido, pode-se dizer que se estabelece uma maior "transparência", "confiança" e "aproximação" entre consumidores e produtores, ao passo que se fortalecem as identidades dos agricultores e das regiões produtoras.

Conforme ressaltam Daviron e Vagneron (2011, p. 3), "ao permitir que consumidores rastreassem os seus produtos até os produtores ou organizações de produtores", tais iniciativas contribuíram para o processo de "descomoditização efetiva dos produtos agrícolas".

Contudo, as certificações se definem também como uma forma de normatização e controle da produção no campo, à medida que a partir de normas definidas em escalas superiores, são impostos aos produtores padrões técnicos e práticas de manejo agrícolas cujo o cumprimento se torna necessário para que obtenham o reconhecimento formal do tipo especial de produção que realizam. Não obstante, de outra modo, pode-se dizer que ao aderirem às certificações, os agricultores tendem, contraditoriamente, a se submeter a uma regulação da produção que é comumente externa ao lugar e que, frequentemente, lhes escapa a capacidade de controle e intervenção ${ }^{2}$.

De acordo com Daviron e Vagneron (2011), a definição de critérios mundialmente estabelecidos para produtos agrícolas certificados - tal como ocorre com os produtos "ecologicamente corretos" e "socialmente justos" - retira dos lugares e regiões produtoras sua identidade, visto que a supervalorização de normas de produção cria uma "cortina" e estabelece um "anonimato" entre quem produz e quem consome, tornando inclusive possível a troca de um produtor por outro - isto é, transformando os "fornecedores" em figuras "substituíveis" -, à medida que o cumprimento de "procedimentos de produção

\footnotetext{
2 As normas definidas para a certificação da produção variam conforme o tipo de selo que se pretende atribuir ao estabelecimento. Contudo, pode-se dizer que tais normas são tanto nacionais como internacionais, públicas ou privadas. As regras para a certificação da produção orgânica, por exemplo, são facultadas a cada país. Assim, caso o produtor queira exportar sua produção orgânica, além da legislação nacional este precisará se adequar também a legislação definida pelo país importador. Por sua vez, para certificações específicas, como a referente a realização de comércio justo (Fair trade) e as de adoção de práticas de sustentabilidade socioambiental (UTZ e Rainforest, por exemplo), os parâmetros são estabelecidos por organizações internacionais, as quais definem os critérios que deverão ser respeitados para a obtenção da certificação pelo produtor.
} 
pré-estabelecidos" torna-se mais importante do que a identidade de "quem realizou a produção".

Ademais, os processos de certificação da produção no campo vêm se constituindo também em um importante mercado que passa a ser explorado, cada vez mais, tanto por empresas certificadoras ${ }^{3}$, como por grandes corporações do agronegócio (especialmente agroindústrias de alimentos), as quais são atraídas pelos elevados ganhos proporcionados pelo mercado de produtos agrícolas certificados ${ }^{4}$. Desse modo, na medida em que tais corporações passam, progressivamente, a atuar tanto no controle do processo de certificação, como também na distribuição e comercialização destes produtos apropriando-se de forma crescente dos excedentes gerados por tais atividades - observase a exacerbação de alguns limites e paradoxos que envolvem, atualmente, o movimento de certificação da produção no campo.

\section{O caso da produção de cacau orgânico certificado no Sul da Bahia: iniciativas de implementação e estratégias de certificação da produção regional}

Desde o final dos anos 1980, a produção de cacau no Sul da Bahia historicamente uma das principais regiões produtoras deste gênero agrícola no Brasil passou a vivenciar uma profunda crise. Consequência, por um lado, de fatores externos como a ascensão de novos países produtores e a queda dos preços internacionais da commodity - associado, por outro lado, a fatores internos - como a redução dos financiamentos agrícolas pelo Estado e a disseminação da praga "vassoura de bruxa" - a

\footnotetext{
3 As empresas certificadoras são entidades privadas responsáveis por fiscalizar, periodicamente, os estabelecimentos produtores certificados (ou candidatos à certificação) e averiguar se os mesmos encontram-se em conformidade com as normas definidas para a concessão do selo. Tal atividade de avaliação de conformidade se constitui em prestação de serviço, e seus custos são pagos pelos produtores que buscam obter ou manter determinada certificação.

${ }^{4}$ Vem se ampliando os exemplos de grandes conglomerados alimentícios que incorporaram em seus portfólios linhas exclusivas de produtos certificados que destacam aspectos como a origem do produto e/ou a adoção de práticas sociais e ecológicas sustentáveis. Considerando-se o caso específico da cafeicultora no Brasil, pode-se citar a linha de cafés denominada "Regiões brasileiras" da empresa Melitta, que valoriza a origem geográfica do produto (COGUETO, 2014). Por sua vez, no caso da produção de cacau e derivados cita-se a linha de chocolates Genuine UTZ, produzida pela Cargill, que possui a certificação de adoção de "boas práticas socioambientais" na produção das amêndoas de cacau. Igualmente, pode-se mencionar a Hershey's, empresa que possui uma linha de chocolates denominada, "Special Dark", cujo cacau utilizado advém de fazendas que recebem a certificação socioambiental Rainforest.
} 
região viu reduzir, drasticamente, tanto sua produção como suas exportações de amêndoas (CHIAPETTI, 2009; 2014; ROCHA, 2008; GOMES; PIRES, 2015).

Apenas entre os anos de 1985 e 2018, a produção de cacau do estado da Bahia regrediu cerca de $69 \%$, decaindo de 361.800 mil toneladas de amêndoas para 113.939 mil toneladas no período (IBGE, 2020). Concomitantemente, o Sul Baiano - região responsável por realizar regularmente cerca de $85 \%$ da produção do estado experimentou também uma vertiginosa queda de suas exportações de cacau, as quais entre 1993 e 2017 decaíram de cerca de 80 mil toneladas para apenas 283 toneladas, revelando desse modo a profunda estagnação na qual imergiu a principal região cacauicultora da Bahia (ROCHA, 2008; SEBRAE, 2019).

Assim, foi diante deste contexto, e com os propósitos de superar a "crise do cacau" vivenciada pelos produtores da região; desvincular a produção local do mercado de commodities; fortalecer modelos de produção ecologicamente sustentáveis; e, agregar maior valor à produção, que, a partir do final dos anos 1990, alguns produtores da região promoveram as primeiras iniciativas de desenvolvimento da agricultura orgânica e valorização de modelos de produção praticados historicamente na região, tal como é o caso do chamado "sistema cabruca", um sistema de produção agroflorestal, realizado em meio a Mata Atlântica ${ }^{5}$ (LOBÃO, 2007; ROCHA, 2008).

Todavia, foi apenas a partir dos anos 2000, com a expansão do consumo nacional e internacional de produtos orgânicos (PIRES, et. al., 2015; DAVIRON; VAGNERON, 2011), e com a sua consolidação como um importante nicho de mercado (SEBRAE, 2019), que uma gama maior de agentes da região, tais como empresas agrícolas, pequenos e médios agricultores capitalizados, cooperativas e agricultores familiares passaram a atuar de maneira regular na produção de cacau orgânico certificado, indicando uma nova dinâmica de especialização produtiva em curso na tradicional região cacaueira.

Em âmbito nacional, a produção de cacau orgânico certificado se constitui tanto num fenômeno recente, como também, pode-se dizer que se define como uma atividade de dimensões modestas, quando comparada com o volume da produção de cacau

\footnotetext{
${ }^{5}$ Segundo Lobão (2007, pág.7) "A palavra cabruca é, possivelmente, uma corruptela do verbo brocar, a qual deu origem a uma outra, cabrocar ou cabrucar, que significa roçar a mata, cortando arbustos e algumas árvores para plantar o cacaueiro".
} 
convencional, tipo bulk ${ }^{6}$. Estima-se que entre 2005 e 2006, a produção brasileira de cacau orgânico atingiu apenas 1.100 toneladas, marca esta que representou menos de 0,6\% do total de amêndoas de cacau produzidas no país (ICCO, 2006) ${ }^{7}$.

$\mathrm{Na}$ Bahia - estado que mesmo após a queda vertiginosa da sua produção ainda conserva a posição de um dos principais centros cacauicultores do país - aquela proporção referente a produção de cacau convencional e orgânico de certo modo também se mantém. Das 105.018 toneladas de amêndoas produzidas pelo estado em 2019 (IBGE, 2020), estima-se que apenas $1 \%$ deva ter sido de cacau orgânico, valor que então corresponderia a pouco mais de 1.000 toneladas de amêndoas ${ }^{8}$ (SANTOS; SANTOS; SANTOS, 2015).

Contudo, ainda que de forma bastante seletiva - tanto territorial como socialmente - os sistemas de produção de cacau orgânico vêm se difundindo no Sul Baiano ao longo das últimas duas décadas. Conforme dados disponibilizados pelo Ministério da Agricultura, Pecuária e Abastecimento (MAPA, 2020), dos 70 municípios que integram a mesorregião Sul da Bahia, 35 possuem atualmente estabelecimentos rurais formalmente reconhecidas como produtores de cacau orgânico (Ver Mapa 1).

Dentre aqueles municípios que concentram o maior número de unidades estão Ibirapitanga e Ilhéus, com 51 estabelecimentos rurais cada, sendo acompanhados por Itacaré, com 28, Camamu, 23, Ibirataia, 12, e Una e Aurelino Leal com 11 estabelecimentos cada. Destaca-se que em todo o estado da Bahia apenas 45 municípios desenvolvem a produção de cacau orgânico, o que indica uma significativa concentração dos municípios produtores daquele modelo de produção no Sul Baiano.

\footnotetext{
6 "Bulk", ou cacau não aromático, corresponde ao cacau padrão, tipo commodity, cuja cotação é definida pelas Bolsas de Nova Iorque e Londres.

${ }^{7}$ Dado o caráter recente do fenômeno de certificação do cacau orgânico, os dados relativos a produção, processamento e exportação deste produto se apresentam ainda bastante escassos. Por isso, apesar da desatualização, optou-se por utilizar nesta pesquisa um dos poucos levantamentos sistemáticos existentes sobre a produção de cacau orgânico, realizado pela Organização Internacional do Cacau (ICCO, 2006).

${ }^{8}$ Inexistem dados oficiais e exatos relativos ao volume da produção baiana de cacau orgânico. Entretanto, em consulta a bibliografias (SANTOS; et. al. 2015; SEBRAE, 2019) e a partir de entrevistas feitas com representantes de produtores, empresas e instituições atuantes na cadeia produtiva do cacau (como a CEPLAC e o Centro de Inovação do Cacau), houve certo consenso na indicação do volume estimado da produção de cacau orgânico no estado da Bahia.
} 
Mapa 1: Bahia - Municípios produtores de cacau orgânico certificado (Março de 2020)

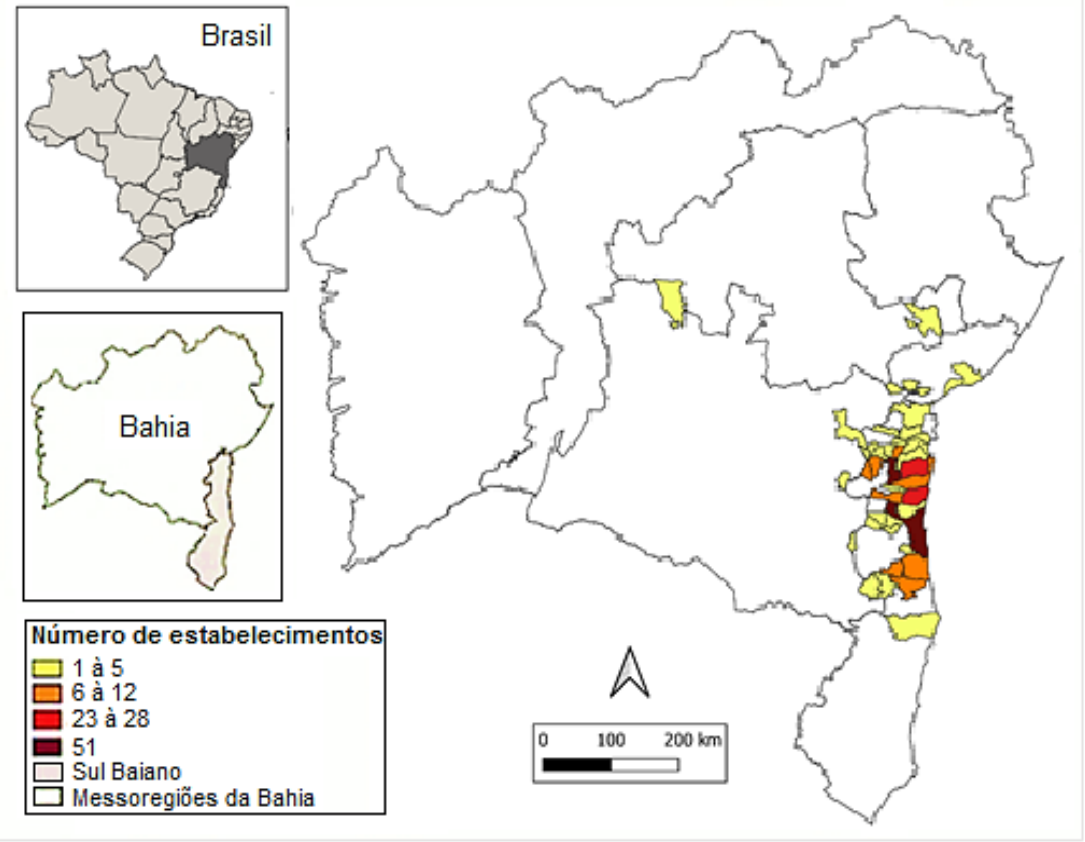

Fonte: MAPA, 2020.

Todavia, deve-se reconhecer que a adesão dos agricultores da região ao sistema de produção de cacau orgânico certificado é ainda bastante restrita. Basta dizer que das milhares de unidades rurais produtoras de cacau existentes em todo o Sul Baiano ${ }^{9}$, pouco mais de 260 são formalmente reconhecidas como produtoras de cacau orgânico pelo Ministério da Agricultura, Pecuária e Abastecimento (MAPA, 2020).

Apesar dos ganhos maiores proporcionados aos agricultores - com preços da arroba que alcançam até $100 \%$ acima daqueles pagos pela produção convencional (ROCHA, 2008) - observa-se que a reduzida adesão dos produtores locais aos novos e mais rentáveis modelos de produção de cacau (como é o caso do cacau orgânico certificado) está relacionada as condições técnicas, financeiras e informacionais que os agricultores precisam dispor para que possam se inserir nos circuitos espaciais de produtos orgânicos certificados.

\footnotetext{
${ }^{9}$ Não é tarefa fácil definir o número de produtores de cacau do Sul Baiano. Segundo o Censo Agropecuário do IBGE (2017), existem cerca de 50.000 estabelecimentos rurais produtores de cacau na região (propriedades com mais de 50 pés de cacau). De acordo com Noia; Midlej; Romano (2015), em 1995, quando ocorreu o lançamento do Programa de Recuperação da Lavoura Cacaueira pelo Governo Federal, a CEPLAC possuía em seu banco de dados com cerca de 8.500 produtores de cacau cadastrados. Por sua vez, conforme a Associação de Produtores de Cacau do Sul Baiano, estima-se que somadas as cooperativas, associações e instituições setoriais que integram a organização, esta representa cerca de 3.000 cacauicultores do Sul Baiano.
} 
Além da necessidade do produtor deter conhecimentos, recursos e equipamentos específicos que permitam ao mesmo pôr em prática as técnicas de manejo da lavoura e beneficiamento das amêndoas definidos como requisitos para o reconhecimento formal da produção orgânica, a certificação da produção impõe outros custos nem sempre capazes de serem pagos pelos agricultores. Na certificação por auditoria, por exemplo, estima-se que apenas para receber a visita técnica de um auditor da empresa certificadora e ter seu estabelecimento inspecionado, os gastos mínimos do produtor variem entre $R \$$ 1.500 à R 2.000 (PENTEADO, 2010) ${ }^{10}$. Por sua vez, de acordo com levantamento feito junto a 1.769 cacauicultores, entre os anos de 2018 e 2019, Chiapetti, Rocha e Conceição (2020) constataram que a renda média mensal oriunda da produção rural obtida pelos produtores do Sul Baiano era de R $\$ 1.414$, sendo que para $50 \%$ deles os rendimentos alcançados eram inferiores a $\mathrm{R} \$ 531,00$.

Mesmo assim, apesar da restrita difusão do sistema de produção de cacau orgânico, pôde-se constatar, nos últimos anos, uma adesão crescente de agricultores do Sul Baiano àquele modelo produtivo. Entre os anos de 2017 e 2020, o número de unidades rurais reconhecidas como produtoras de cacau orgânico na região aumentou cerca de $350 \%$, saltando de 62 para agora alcançar 266 estabelecimentos (MAPA, 2020).

A partir dos dados disponibilizados pelo Cadastro Nacional de Produtores Orgânicos, é possível também constatar que produtores rurais, cooperativas e empresas agrícolas do Sul Baiano estão adotando caminhos e estratégias diferentes para alcançar a certificação de seus estabelecimentos agrícolas. Enquanto 82 unidades rurais recorrem, atualmente, a certificação por auditoria, as demais 184 , ou seja, quase $70 \%$ do total de estabelecimentos cadastrados valem-se do sistema de certificação participativa para obter o reconhecimento formal do sistema especial de produção que praticam (Tabela 1).

\footnotetext{
10 Além da eventual contratação de consultores especializados para auxiliar o produtor a adequar a propriedade e a lavoura aos parâmetros estabelecidos para a certificação, a necessária realização de medidas técnicas, tais como: a preparação do solo para retirada de adubos químicos; a instalação de infraestruturas especiais para a armazenagem e tratamento das amêndoas orgânicas; o emprego de equipamentos exclusivos para o cultivo da lavoura orgânica (pulverizador, maquinários, etc.); além do tamanho da propriedade a ser certificada, constituem-se em outros fatores que tendem a elevar ainda mais os custos dos agricultores, tudo isso se constituindo em obstáculo para que grande parte dos produtores de cacau da região alcancem a certificação formal dos seus estabelecimentos.
} 
Tabela 1: Mesorregião Sul da Bahia: Número de estabelecimentos rurais produtores de cacau orgânico segundo o tipo de instituição certificadora (Março de 2020)

\begin{tabular}{clc}
\hline Tipo & \multicolumn{1}{c}{ Nome } & $\begin{array}{c}\text { Número de estabelecimentos } \\
\text { certificados }\end{array}$ \\
\hline Empresa & IBD - Certificações & $\mathbf{8 2}$ \\
\hline OPAC & Rede Povos da Mata & $\mathbf{1 8 4}$ \\
\hline & Total & $\mathbf{2 6 6}$ \\
\hline
\end{tabular}

Fonte: MAPA, 2020.

Deve-se destacar que o sistema de certificação por auditoria e o sistema de certificação participativa apoiam-se em princípios e estruturas organizacionais distintos para o reconhecimento legal da produção orgânica realizada pelos estabelecimentos rurais. Enquanto o primeiro se caracteriza pelo protagonismo e centralidade assumidos pelas empresas certificadoras - as quais são contratadas pelos produtores para avaliar, vertical e unilateralmente, se as propriedades estão em conformidade com os padrões técnicos de produção estabelecidos para o reconhecimento formal da produção orgânica - a certificação participativa baseia-se na atuação direta dos próprios agricultores, os quais, contando com o envolvimento de outros agentes (como consumidores, indústrias processadoras, empresas exportadoras, Ongs) e organizados através de Organismos Participativos de Avaliação de Conformidade (OPACs) $)^{11}$, realizam uma espécie de "auto certificação", isto é, promovem uma forma de "controle social" da produção.

Desse modo, com o objetivo de avaliar estes dois tipos distintos de certificação da produção de cacau orgânico existentes no Sul da Bahia, analisaremos os casos da Cooperativa de Produtores Orgânicos do Sul da Bahia (Cooperativa Cabruca), marcada pela realização de uma produção orgânica baseada no sistema de certificação por auditoria, assim como a Associação Povos da Mata Atlântica do Sul da Bahia (Rede

\footnotetext{
${ }^{11}$ Os Organismos Participativos de Avaliação de Conformidade se constituem em figuras jurídicas previstas pelo Sistema Brasileiro de Avaliação da Conformidade Orgânica (SisOrg), e devem estar cadastradas no Ministério da Agricultura, Pecuária e Abastecimento. Semelhante às empresas certificadoras, os OPACs tem a obrigação de verificar se os estabelecimentos produtores ou processadores à eles vinculados atendem as exigências estabelecidas pela regulamentação brasileira de produção orgânica. Assim, os OPACs são formalmente responsáveis por realizar a certificação dos estabelecimentos à ele associados. Entretanto, diferente das empresas certificadoras, o funcionamento dos OPACs está baseada em dois princípios: o "controle social" da produção - no qual os próprios produtores integrantes da organização participam diretamente das tarefas coletivas de avaliação da conformidade dos estabelecimentos - e a "responsabilidade solidária" - na qual todos os integrantes assumem o compromisso de cumprir as exigências legais para o reconhecimento formal da produção orgânica, responsabilizando-se pela credibilidade da certificação.
} 
Povos da Mata), caracterizada por realizar uma produção de cacau orgânico baseada no sistema de certificação participativa.

O intuito com a apresentação destas experiências de produção, foi o de avaliar até que ponto a adoção de diferentes modelos de certificação possibilitam aos agricultores e a região produtora obterem uma maior autonomia (política e econômica), tornarem-se menos subordinados às grandes corporações do agronegócio, e impulsionar um desenvolvimento regional mais justo e igualitário.

\section{Experiências de certificação da produção de cacau orgânico no Sul Baiano}

A Cooperativa Cabruca e a certificação por auditoria: uma expressão da regulação vertical da produção no campo

Considerada uma das instituições precursoras da realização da produção agrícola orgânica na região cacaueira, a Cooperativa dos Produtores Orgânicos do Sul da Bahia Cooperativa Cabruca - foi criada em dezembro de 2000 em Ilhéus, Bahia, e nasceu da associação de produtores rurais interessados em fortalecer o movimento de difusão de modelos de produção agrícola ecologicamente sustentáveis (iniciado na região na década anterior); valorizar práticas de produção desenvolvidas historicamente no Sul Baiano (como é o caso do sistema de produção "cabruca", um sistema de lavoura sombreada, realizado em consórcio com a Mata Atlântica); e, promover o fortalecimento dos pequenos e médios produtores rurais da região, através da associação destes à cooperativa e do estímulo a uma maior articulação entre os mesmos.

Atualmente, a Cabruca conta com 28 produtores cooperados e 30 estabelecimentos vinculados, os quais se distribuem por oito municípios do Sul Baiano, dentre eles: Ilhéus (com 8 estabelecimentos), Uruçuca (7), Una (7), Buerarema (3), Itacaré (2), Barro Preto (1), Pau Brasil (1) e Almadina (1) (Ver Mapa 2). Apesar de terem o cacau orgânico e biodinâmico $^{12}$ certificados como seus principais produtos, estes

\footnotetext{
12 Para Penteado (2010, pág.92) são dois os aspectos que caracterizam a agricultura biodinâmica: o "Uso de preparados [...] de origem mineral, vegetal e animal altamente diluídos, que potencializam forças naturais para vitalizar e estimular o crescimento das plantas ao serem aplicados no solo e sobre os vegetais", [e a realização de] “(...) operações agrícolas (plantio, poda, raleio e outros tratos culturais e colheita) de acordo com o calendário astral”.
} 
estabelecimentos também cultivam outros gêneros agrícolas, tais como o guaraná, a pupunha, o açaí, o cravo, a noz moscada, a goiaba, a banana entre outros produtos, revelando a diversidade de cultivos como uma prática comum de muitos cooperados (CABRUCA, 2020).

Mapa 2: Bahia - Localização dos estabelecimentos associados à Cooperativa Cabruca (Março de 2020)

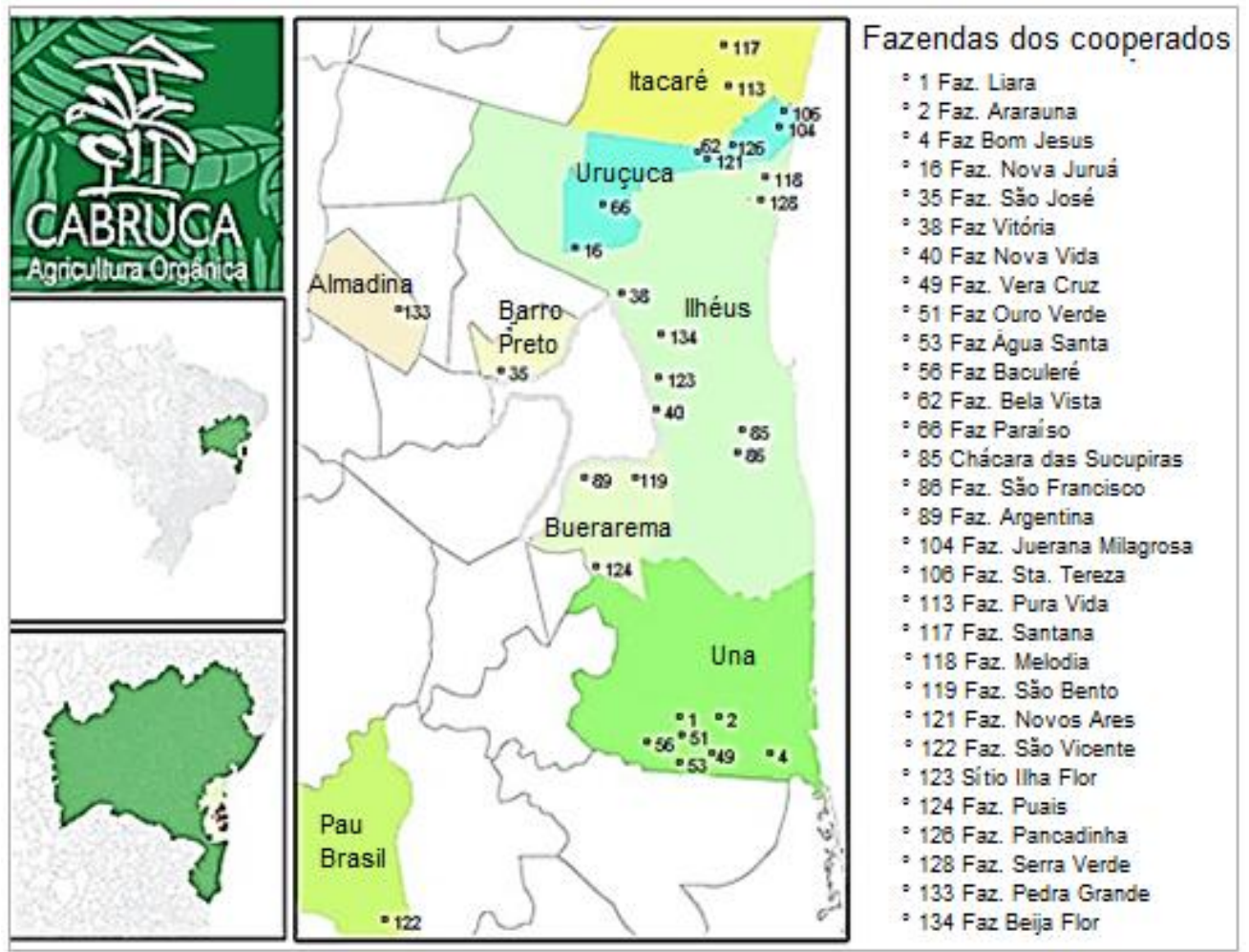

Fonte: CABRUCA, 2020.

Para receber o selo de produtor "orgânico" ou "biodinâmico", os estabelecimentos vinculados a Cooperativa Cabruca são inspecionados pelo Instituto Biodinâmico (IBDCertificações), empresa certificadora sediada no interior do estado de São Paulo que avalia os produtores da Cooperativa desde a sua fundação. Através da contratação dos serviços de auditoria, a IBD-Certificações realiza visitas anuais aos agricultores cooperados e, nas suas inspeções aplica critérios de avaliação da produção orgânica pautados tanto na legislação brasileira como em normas internacionais (sobretudo dos EUA e União Europeia) para a atribuição da certificação ao produtor. Assim, através de um controle vertical da produção observa-se a sujeição do produtor às normas e regulamentos externos aplicados pela empresa certificadora; um procedimento 
estabelecido como condição para que os produtores obtenham o reconhecimento e a valorização da sua produção.

Deve-se destacar que além da empresa certificadora, a própria Cooperativa Cabruca também realiza um importante papel na regulação do processo de produção e comercialização das amêndoas de cacau produzidas pelos seus associados. Vale esclarecer que os produtores não têm a obrigação de entregar sua produção para a cooperativa comercializá-la, como também, por outro lado, a mera associação deles à cooperativa não garante que a sua produção será necessariamente aceita por ela para posterior distribuição. Isso porque, o recebimento da produção pela Cooperativa Cabruca está sempre sujeita a um controle interno realizado pela mesma, a qual submete os lotes recebidos dos seus cooperados a testes físicos, visuais e olfativos que determinarão o aceite ou a rejeição do lote ${ }^{13}$. Nos casos em que o lote não é aceito, o produtor não consegue comercializar suas amêndoas através da cooperativa, contudo, estes frequentemente vendem sua produção em outros locais, ainda que esta passe a ser reconhecida apenas como uma produção convencional, tipo bulk.

As amêndoas de cacau certificado produzidas pelos cooperados e entregues à Cooperativa Cabruca para comercialização são distribuídas tanto para o mercado interno como para o mercado externo. Comumente, os compradores entram diretamente em contato com a Cooperativa, a qual se incumbe pela negociação e comercialização dos lotes. Dada a natureza especial do modelo de produção agrícola praticado e a qualidade superior do cacau produzido pelos cooperados, algo avaliado pela certificadora e atestado também pela própria Cooperativa, os compradores do cacau costumam ser, na maioria das vezes, chocolaterias nacionais e internacionais, mas também, ocasionalmente, aparecem como interessadas empresas atuantes em outros ramos dos circuitos de produção de cacau e derivados, como é o caso da indústria de cosméticos.

No caso da Cooperativa Cabruca, em que pese a irregularidade das solicitações de compra do cacau produzido pelos seus cooperados, esta já realizou a comercialização da sua produção tanto para chocolaterias nacionais, especializadas em produtos finos e orgânicos (como a AMMA, Indústria Brasileira de Cacau, além de pequenas fábricas de

\footnotetext{
${ }^{13}$ A princípio é retirado uma amostra para ser avaliada através do teste conhecido como "corte do cacau". Os seguintes critérios são avaliados visualmente e olfativamente: fermentação, acidez e a presença de vestígios de fumaça. Essa avaliação revela como foi executado o pós-colheita e serve de indicativo para a caracterização da qualidade das amêndoas apresentadas pelo produtor.
} 
chocolatiers), como também para chocolaterias internacionais, especialmente europeias, como são os casos das suíças Felchlin, Läderach e Stella Bernrain. A Cooperativa também já manteve relações com a empresa de cosméticos Natura, indústria brasileira, com sede no estado de São Paulo, e que tem em seu portfólio linhas de produtos especiais, cuja matéria-prima é produzida a partir de modelos de produção "sustentáveis", que preconizam a preservação da fauna e da flora brasileira.

É valido salientar que a produção de amêndoas de cacau pelos cooperados tem uma escala modesta, alcançando, juntos, menos de 100 toneladas por ano. Entretanto, ainda que pequena esta produção costuma alcançar valores bem acima daqueles atribuídos para o cacau convencional, possibilitando assim ao produtor alcançar melhores remunerações com o resultado da sua produção. Em entrevista realizada com agricultor associado a Cooperativa Cabruca, este relatou que as amêndoas orgânicas apresentam valores quase três vezes acima dos preços pagos pelo cacau convencional, tipo bulk. Isso seria resultado tanto da qualidade superior e certificação da sua produção, como também é possibilitado pela negociação, sem agentes intermediadores, com compradores (inter)nacionais.

Atualmente, além da produção e comercialização direta de amêndoas de cacau, a Cooperativa vem estabelecendo novas estratégias com o objetivo de ampliar a autonomia econômica dos produtores e agregar maior valor à sua produção. Através da implantação de uma pequena fábrica de beneficiamento e processamento de amêndoas, a cooperativa passou gradativamente a produzir derivados de cacau, como o nibs ${ }^{14}$, bem como iniciou a produção de sua própria marca de chocolate orgânico e biodinâmico, utilizando-se do cacau produzido pelos seus cooperados (Imagem 1). Deste modo, observa-se o importante papel realizado pela Cooperativa na articulação dos produtores e na viabilização de projetos comuns, capazes de proporcionar maior identidade e autonomia aos cooperados.

\footnotetext{
${ }^{14} \mathrm{O}$ nibs resulta da torrefação e do trituramento das amêndoas do cacau e serve de base para a transformação do cacau em outros (sub)produtos.
} 
Imagem 1: Chocolates orgânico e biodinâmico produzidos pela Cooperativa Cabruca

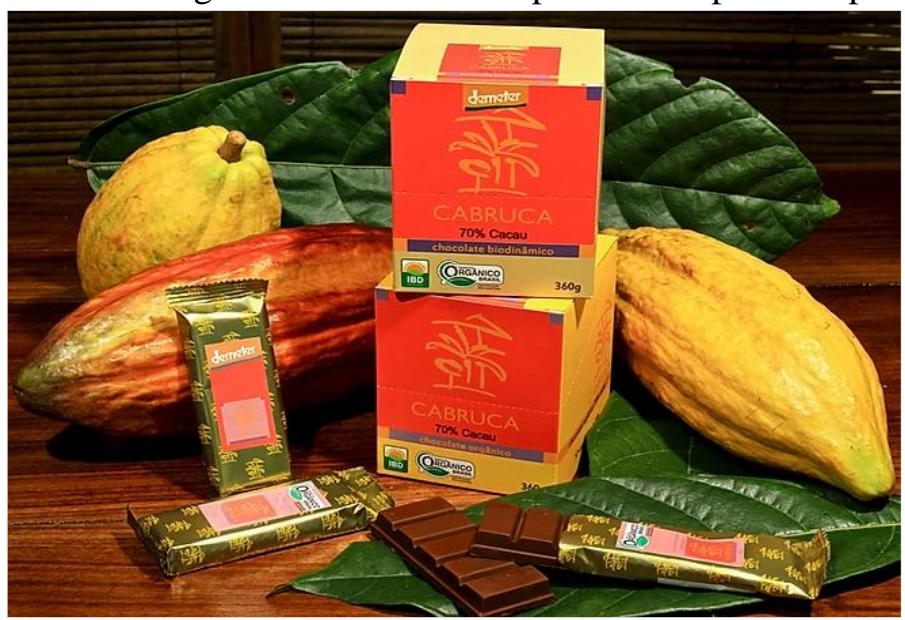

Fonte: CABRUCA, 2020.

Apesar da Cooperativa Cabruca contar hoje com 28 filiados ativos, este número representa apenas uma pequena fração do total de produtores que já estiveram vinculados à instituição. Conforme informações concedidas pela própria Cooperativa, já foram associados a ela cerca de 150 produtores durante seus vinte anos de existência, o que revela uma certa dificuldade de permanência destes junto a Cabruca. Diversos são os fatores que podem explicar esta impermanência dos produtores na Cooperativa e suas eventuais dificuldades em praticar a produção orgânica certificada.

Vale novamente destacar que a certificação por auditoria impõe, de maneira geral, custos relativamente altos para a realização das vistorias; estabelece critérios técnicos rigorosos para a avaliação dos produtores; e exige o pagamento anual de taxas, tudo isso desfavorecendo a incorporação e a permanência de produtores menos capitalizados àquele modelo de certificação da produção ${ }^{15}$. No caso da Cooperativa Cabruca, deve-se ainda considerar o controle interno sobre o recebimento e comercialização da produção realizada pela mesma, prática esta que leva, algumas vezes, a cooperativa a rejeitar a produção de amêndoas dos seus próprios cooperados. Apesar da agricultura orgânica trazer também o propósito de viabilizar a participação dos pequenos e médios produtores em um modelo mais rentável de produção, a presença das empresas certificadoras, assim como a realização de um controle rígido e vertical da produção - sem desconsiderarmos

\footnotetext{
${ }^{15}$ Em entrevista realizada com o agricultor "Joaquim", ex-cooperado da Cabruca, este relatou que devido ao fim do Instituto de Estudos Socioambientais do Sul da Bahia, antes responsável por financiar as visitas técnicas da IBD-Certificações aos estabelecimentos de pequenos agricultores, ele teve dificuldades para pagar as visitas da certificadora, o que ocasionou a perda do selo de produtor orgânico de seu estabelecimento. Atualmente o agricultor está vinculado à Rede de Agroecológica Povos da Mata.
} 
as limitações técnicas, financeiras e informacionais dos produtores para a adaptação dos seus estabelecimentos - tendem a constituir obstáculos à participação e a permanência de muitos produtores nos modelos de produção agrícola certificada.

De acordo com Daviron e Vagneron (2011), a certificação por auditoria tem ampliado-se devido o interesse de muitos grupos com o crescimento e a rentabilidade do mercado de produtos orgânicos. Contudo, para os autores,

[...] a capacidade de relatar e documentar está se tornando o principal fator de desempenho (e uma das principais causas de exclusão dentro das cadeias de suprimentos), até o ponto de tornar as coisas auditáveis, (Rotinas e padrões de certificação) mais importante do que o conteúdo do próprio modelo de produção proposto (DAVIRON; VAGNERON, 2011, p. 21).

Segundo Daviron e Vagneron (2011), a proposta de valorização dos modelos alternativos de produção e fortalecimento dos pequenos produtores vem se fragilizando devido a rigidez dos padrões e critérios estabelecidos pelas certificadoras. Dessa forma, segundo os autores ocorre uma espécie de re-commoditização, visto que os processos que antes tinham como objetivo distanciar os produtores e as regiões do mercado convencional de commodities, através da valorização das especificidades das produções locais e da construção de uma maior independência dos produtores, têm perdido alguns de seus propósitos originais, haja visto que as certificadoras atuam como obstáculos (financeiro e técnico) à inclusão de grupos minoritários, impondo uma racionalização estrita ao campo e negligenciando os outros objetivos que justificavam e legitimavam o movimento de difusão da produção orgânica (como a busca pela maior inclusão dos pequenos produtores às cadeias de valores e a promoção de um desenvolvimento mais equânime no campo).

Não obstante, juntamente com Santos (2005, p. 148), poderíamos também dizer que na medida em que "as novas variáveis não se difundem de maneira uniforme" pelo território, "a geografia assim recriada torna-se ainda mais desigualitária". Porém, tratamse de desigualdades de "um tipo novo, já por sua constituição, já por seus efeitos sobre os processos produtivos e sociais".

A Rede Povos da Mata e a certificação participativa: uma possibilidade de regulação horizontal da produção no campo 
Criada oficialmente em 2015, pode-se dizer que a Rede Povos da Mata surge da articulação de dezenas de pequenos produtores rurais do litoral Sul Baiano e do interesse comum destes em fortalecer suas produções através do desenvolvimento da agricultura orgânica e da busca pela inserção nos circuitos espaciais de produtos agrícolas certificados. Estes agricultores, dentre os quais incluíam-se representantes de quilombolas, indígenas, agricultores familiares e produtores assentados, fundaram um OPAC - a Associação Povos da Mata Atlântica do Sul da Bahia de Certificação Participativa - como estratégia para contornar as dificuldades, sobretudo técnicas e financeiras, que encontravam para obter a certificação formal da produção orgânica que há tempos muitos já realizavam.

Para iniciar suas atividades, a Povos da Mata contou em um primeiro instante com o apoio da Rede Ecovida, um OPAC criada em 1998, atuante na região Sul do Brasil e voltada exclusivamente a prática da agroecologia. Esta organização, composta essencialmente por agricultores familiares, é considerada uma das instituições pioneiras na realização da certificação participativa no país, e forneceu orientação e apoio técnico para que a Rede Povos da Mata iniciasse suas atividades institucionais e de capacitação de produtores rurais do Sul da Bahia ${ }^{16}$.

Apesar de poucos anos de existência, a Rede Povos da Mata vem apresentando uma rápida expansão, o que sinaliza para o grande interesse dos pequenos produtores rurais do estado em se inserir no modelo de produção agrícola certificado, e assim conquistarem uma maior autonomia econômica. De 20 famílias de agricultores inicialmente vinculados à Rede, atualmente ela possui cerca de 700 famílias filiadas, conforme informações fornecidas pela instituição (POVOS DA MATA, 2020). No decorrer deste curto intervalo de tempo, viu-se também expandir de forma marcante a territorialidade da Rede no estado da Bahia. Com o crescimento do número de famílias vinculadas à instituição, o território de atuação do grupo (o litoral Sul Baiano) foi ampliado, passando agora a abarcar municípios de outras regiões do estado, os quais são agrupados, pela própria instituição, em quatro núcleos regionais, a saber: Monte Pascoal, Serra Grande, Pratigi e Raízes do Sertão. Assim revela-se uma territorialidade que

\footnotetext{
${ }^{16}$ Informações concedidas por "Maria", ex-dirigente da Rede Povos da Mata.
} 
ultrapassa os limites regionais do Sul da Bahia, região na qual a Rede Povos da Mata estava inicialmente inscrita (Mapa 3).

Mapa 3: Bahia - Núcleos regionais da Rede Povos da Mata, 2018

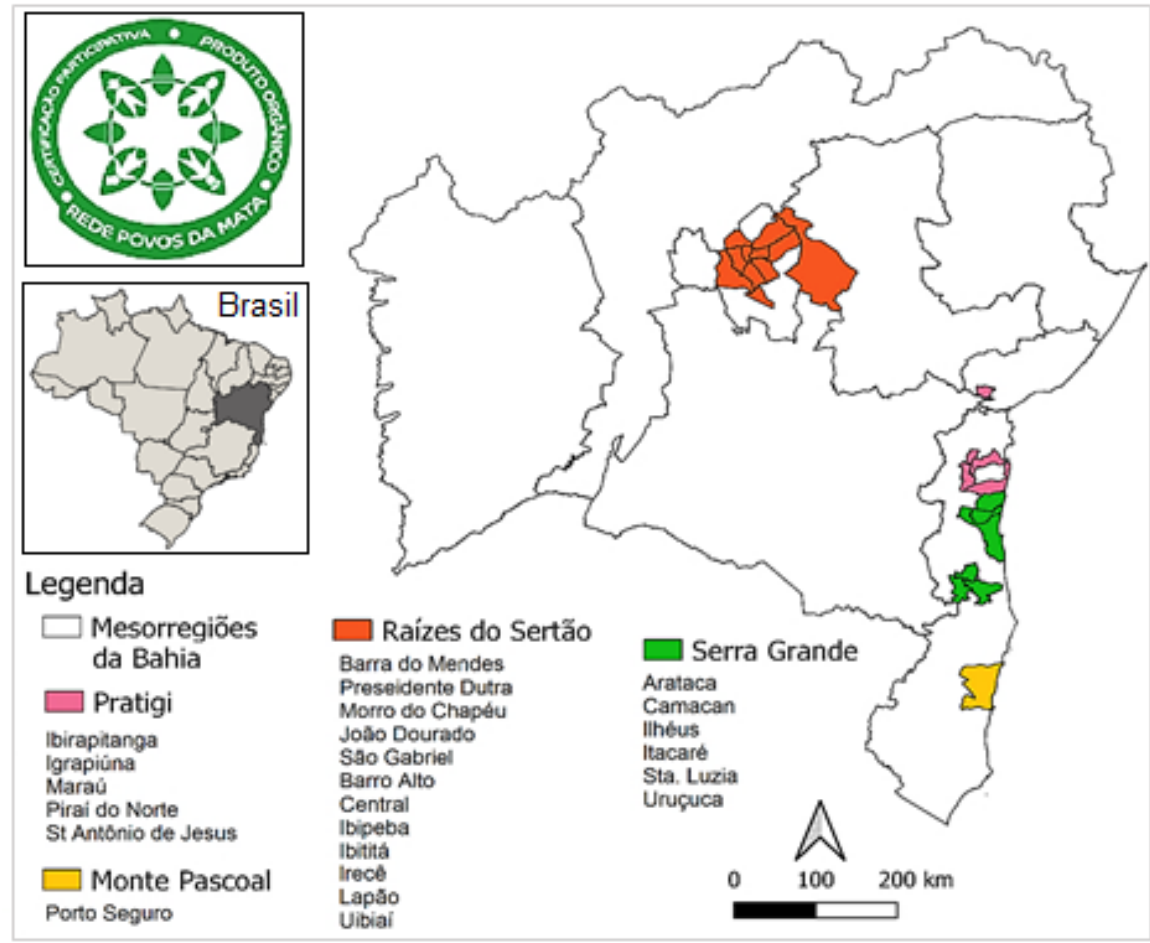

Fonte: FARRAN, 2019.

A certificação da produção agrícola realizada pela Povos da Mata está baseada nos princípios da certificação participativa, ou seja, trata-se de um "controle social da produção", o que significa que cabe aos próprios produtores rurais realizarem a fiscalização e o reconhecimento formal do modelo de produção agrícola praticado pelos demais integrantes da organização. Para tanto, as cerca de 700 famílias que integram a Rede são subdivididas em 40 grupos de agricultores, os quais, periodicamente, são responsáveis por visitar e inspecionar os estabelecimentos dos demais integrantes da Rede. Além desta estrutura organizacional para a avaliação dos estabelecimentos rurais, a Povos da Mata também mantém núcleos locais compostos por agricultores (eleitos para exercerem as funções de coordenador, subcoordenador e secretário de núcleo), os quais são responsáveis por representar seu respectivo grupo nas reuniões gerais promovidas pela Rede para discutir os problemas dos produtores, organizar atividades de capacitação técnica dos membros, definir as estratégias de ação e elaborar os projetos coletivos da instituição. 
A rápida expansão da Rede Povos da Mata no estado da Bahia demonstra, de certa forma, uma ampliação das articulações territoriais e um fortalecimento das relações horizontais entre, especialmente, os pequenos produtores baianos. Dentre as razões que explicam esta rápida e significativa adesão dos produtores à Rede, estão: os baixos custos e a ausência de taxas para a inspeção e a certificação dos estabelecimentos rurais associados (atividades estas realizadas pelos próprios produtores e que, na certificação por auditoria se constituem em gastos relativamente altos para pequenos agricultores); além do apoio e auxílios técnicos fornecidos pela própria Rede aos agricultores, algo fundamental para a adequação dos estabelecimentos rurais aos padrões técnicos de produção exigidos para o reconhecimento formal da prática da agricultura orgânica.

No que diz respeito especificamente a produção de cacau orgânico no Sul da Bahia, a Rede Povos da Mata é responsável por certificar 184 estabelecimentos, os quais encontram-se distribuídos por 15 municípios da região (MAPA, 2020). Ibirapitanga é o município que concentra o maior número de unidades rurais certificadas pela organização, com 51 estabelecimentos, sendo acompanhada por Ilhéus, com 39, Camamu, 23, Itacaré, 21, além de Maraú (10), Santa Luzia (8), Piraí do Norte (7), Arataca (6), Ipiaú (5), Igrapiúna (4), Uruçuca (3), Nilo Peçanha (2), Valença (2), Nova Ibiá (2) e Gandu (1) (Mapa 4).

Os produtores vinculados à Rede realizam, de maneira geral, uma produção diversificada, sendo o cacau apenas um dos gêneros agrícolas cultivados pelos integrantes (também são produzidas frutas, verduras, hortaliças, legumes, entre outros). Não obstante, pela própria característica dos produtores (pequenos agricultores familiares descapitalizados, em sua maioria) e a natureza diversificada de suas lavouras, a produção de cacau e derivados (como amêndoas beneficiadas, nibs e chocolates) pelo grupo se caracteriza por ser realizada, comumente, em pequena escala e se insere principalmente em circuitos espaciais de produção que operam em âmbito local, regional e nacional. 
Mapa 4: Bahia - Localização dos estabelecimentos produtores de cacau orgânico credenciados pela Rede Povos da Mata (Março de 2020)

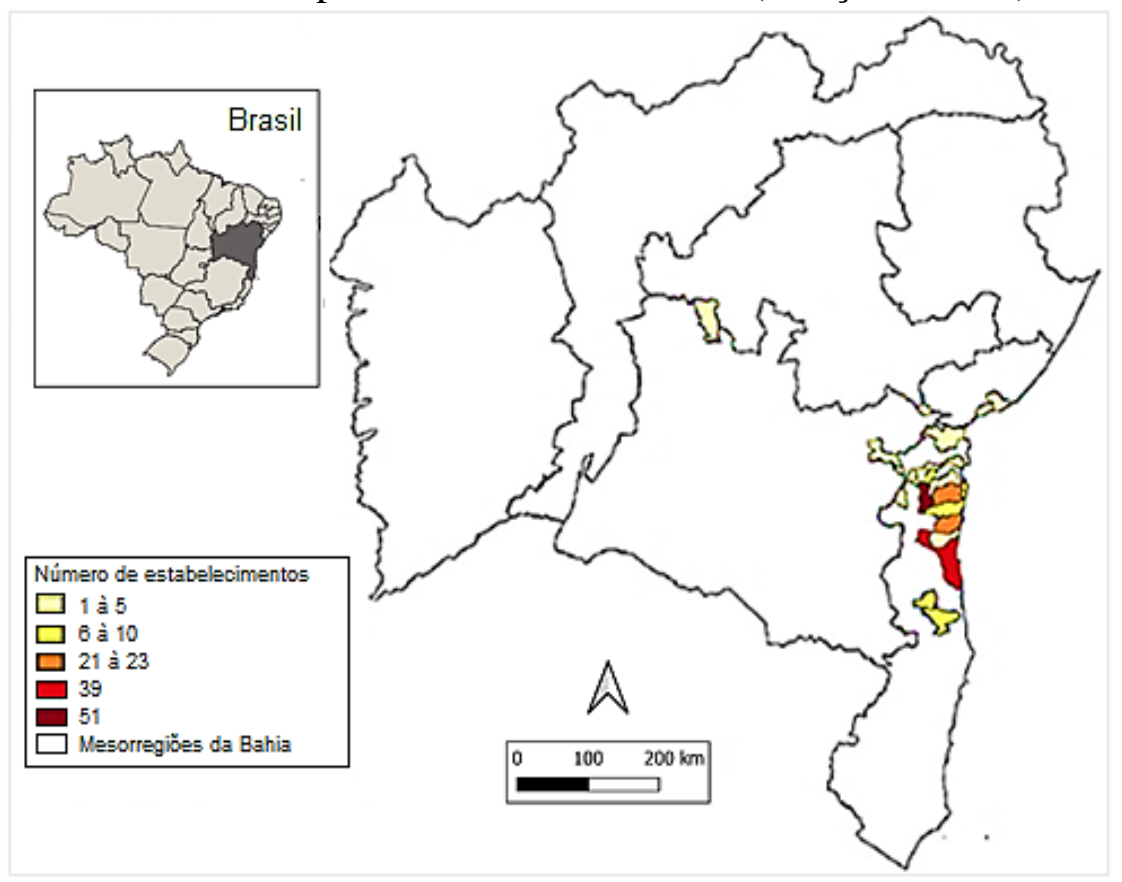

Fonte: MAPA, 2020.

A venda dos produtos da Rede Povos da Mata é, muitas vezes, realizada através de feiras organizadas pelo próprio grupo em parceria com prefeituras e associações de produtores, e possuem o objetivo de facilitar a logística de distribuição e reduzir o número de intermediários na comercialização dos produtos. As chamadas "Estações orgânicas", se constituem em entrepostos regulares de venda e entrega de mercadorias localizadas em cidades do Sul Baiano onde a Povos da Mata possui maior inserção, tais como: Itabuna, Itacaré, Uruçuca, Maraú, Ibirapitanga e Irecê (POVOS DA MATA, 2020). Os agricultores integrantes da Rede vendem seus produtos, e/ou entregam suas "cestas" (encomendadas, antecipadamente, por redes sociais) nas estações e feiras de produtos orgânicos realizadas nas cidades próximas de suas propriedades rurais. Através desta estratégia de distribuição da produção, os agricultores fortalecem sua identidade, estabelecendo relações diretas com os compradores, além de promoverem e fortalecerem o desenvolvimento de circuitos locais e regionais de produção, distribuição e consumo.

Além desses circuitos produtivos locais e regionais, a Rede Povos da Mata também mantém relações de distribuição e comercialização de seus produtos com organizações sociais localizadas em outras regiões do Brasil. Este, por exemplo, é o caso do fornecimento pela Povos da Mata de derivados de cacau à Rede Ecovida, organização 
civil de agricultores orgânicos que revende esses produtos nos estados em que atua, dentre eles: Paraná, Santa Catarina, Rio Grande do Sul e São Paulo.

Os produtores da Povos da Mata também fornecem amêndoas de cacau para médias e grandes chocolaterias brasileiras. Estes, por exemplo, são os casos da AMMA e da Dengo, empresas que produzem chocolates orgânicos e com qualidade superior e que distribuem sua produção em escala nacional, dispondo inclusive de lojas especializadas próprias localizadas em grandes centros urbanos do país, tais como: São Paulo, Rio de Janeiro e Salvador (MERCADO DO CACAU, 2019). Através da exposição do processo geral de produção do chocolate - a começar pela atividade dos pequenos e médios agricultores em suas lavouras sombreadas de cacau, passando pelo processamento nas fábricas, até sua venda nas lojas de chocolate especializadas - aquelas empresas buscam incorporar aos seus produtos os "marcos de distinção" da produção realizada no Sul Baiano (fundada no sistema agroflorestal cabruca e baseada na pequena produção familiar); uma estratégia que promove a diferenciação e a valorização tanto mercantil como simbólica dos produtos daquelas empresas.

Apesar de relativamente pequena, a produção de cacau orgânico e de nibs realizada pela Rede Povos da Mata vem se mostrando bastante rentável. Conforme informação concedida por membro da organização, enquanto o preço da arroba do cacau bulk pago aos produtores na Bahia oscilou entre $\mathrm{R} \$ 98,00$ e $\mathrm{R} \$ 105,00$ em julho de 2017, o cacau orgânico certificado comercializado pela Rede Povos da Mata alcançou $\mathrm{R} \$ 270,00$, e o nibs atingiu $\mathrm{R} \$ 160$ o quilo, valores que garantiram aos produtores da Rede melhores remunerações pela sua produção.

Outra estratégia da Rede para agregar valor à sua produção de cacau, e viabilizar a maior autonomia econômica dos seus membros, vem sendo a busca pela ampliação da capacidade de beneficiamento do cacau e produção de chocolate orgânico certificado pelos agricultores associados à instituição. Atualmente, entre as dezenas de estabelecimentos produtores de cacau filiados à Rede, pouquíssimos dispõem de meios para realizar o processamento do cacau. Estes, por exemplo, são os casos das pequenas fábricas artesanais Ubá, Mahat e Chocolate da Mata criadas por produtores associados à Povos das Mata (Imagem 2). Contudo, através do envolvimento da Rede em projetos que contam com a participação de outras instituições, observam-se o desenvolvimento de ações que tem o propósito de disponibilizar aos agricultores recursos para viabilizar o 
processamento do cacau por eles produzido. Este é o caso do Assentamento Dois Riachões, localizado no município de Ibirapitanga/BA, certificado pela Rede Povos da Mata e que vem recebendo financiamento da ONG Tabôa - Fortalecimento Comunitário para a implantação de infraestrutura de beneficiamento de amêndoas e produção de chocolates orgânicos e de qualidade superior (MERCADO DO CACAU, 2019).

Imagem 2: Chocolates orgânicos certificados produzidos por membros da Rede Povos da Mata.

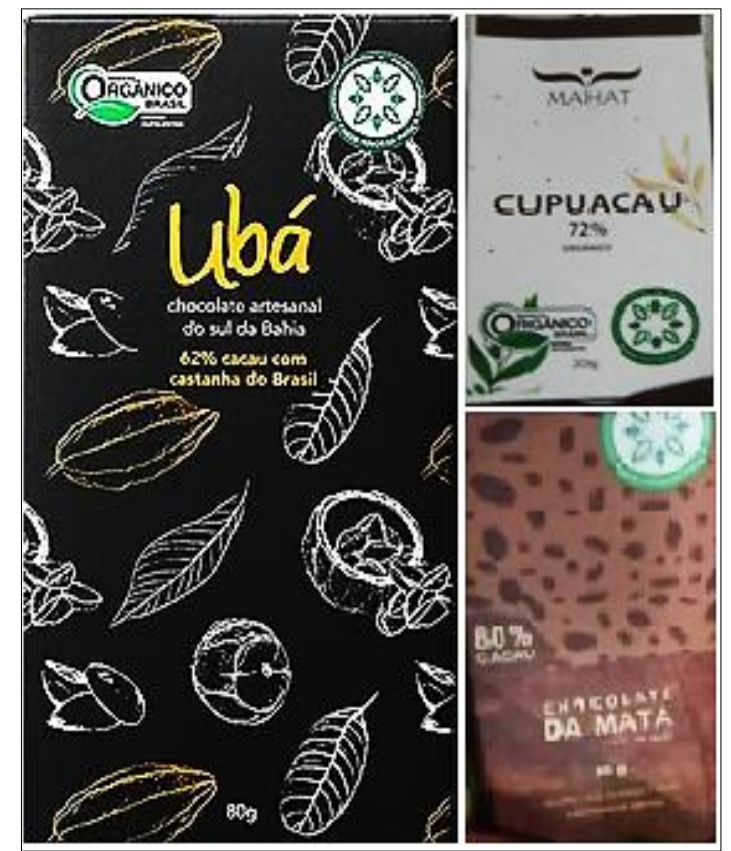

Fontes: chocolateuba.com.br; cacauechocolate.com.br; facebook.com/povosdamata/.

As dificuldades da Rede Povos da Mata para a realização de suas atividades não são poucas e, pode-se dizer que também são crescentes. Isto porque, a escassez de recursos da instituição (e da maioria de seus integrantes) para a realização de seus projetos é marcante; a necessidade de capacitação técnica dos membros da organização para a implantação e reconhecimento da prática da agricultura orgânica é permanente; a composição dos grupos de avaliação e certificação dos estabelecimentos vinculados a instituição despende custos e exige o treinamento especial de membros voluntários; e, a incorporação constante e em escala crescente de novos membros à organização se configura como um grande desafio tanto para a realização das atividades técnicas de inspeção e certificação dos produtores, como para a compatibilização de interesses e a construção de projetos comuns. 
Contudo, através da experiência da Rede Povos da Mata nota-se a força dos pequenos produtores, à medida que estes ao mesmo tempo em que se adequam aos novos movimentos do mercado de produtos agrícolas certificados, através da construção de solidariedades e a partir da defesa de seus interesses produzem ações dotadas de um sentido econômico e político emancipador, visto que orientadas a proporcionar uma maior autonomia dos produtores, fortalecer suas identidades, e proporcionar uma melhoria de suas condições de vida. Ademais, a forma de organização e atuação do grupo é caracterizada tanto pelas relações horizontais estabelecidas - fundadas na construção de uma cooperação entre os membros do grupo e na partilha de um projeto comum -, como também se baseia na criação de solidariedades organizacionais, necessárias para a realização do processo formal de (auto)certificação dos produtores.

Diante disso, a atuação territorial e a estrutura organizativa da Rede Povos da Mata convida-nos, inevitavelmente, a refletir sobre a relevância das relações horizontais para a organização produtiva do espaço regional, assim como sua importância para a construção de uma maior autonomia política e econômica dos agentes locais. Conforme ressalta Santos (2005, p. 151),

As horizontalidades são o domínio de um cotidiano territorialmente partilhado com tendência a criar suas próprias normas, fundadas na similitude ou na complementaridade das produções e no exercício de uma existência solidária. Nesses subespaços, e graças a essa solidariedade, consciente ou não, há um aumento da produtividade econômica, mas também da produtividade política, alimentadas pela informação.

Deste modo, partilhamos da ideia de Santos (2005, p. 144) quando este ressalta que as ampliações das "uniões horizontais, mediante as novas formas de produção e consumo", permitem também aos produtores "defender seus interesses", fazendo com que suas ações deixem de ter um sentido puramente econômico para, através de alianças e a construção de projetos comuns, assumir um caráter político, "localmente definido e que também distingue as regiões brasileiras umas das outras" ${ }^{\prime 17}$.

\footnotetext{
17 “'(...) uniões horizontais podem ser ampliadas, mediante as próprias formas novas de produção e consumo. Um exemplo é a maneira como os produtores rurais se reúnem para defender os seus interesses, o que lhes permitiu passar de um consumo puramente econômico, necessário às respectivas produções, a um consumo político localmente definido e que também distingue as regiões brasileiras umas das outras" (SANTOS, 2005, p.144).
} 
Mesmo que seus efeitos ainda sejam social e territorialmente limitados, as práticas e as articulações territoriais promovidas pela Rede Povos da Mata constituem-se numa "resposta dos lugares" ao modelo agrícola dominante e a inclusão seletiva de produtores rurais produzida pela certificação por auditoria, a qual, sob a orientação de uma racionalidade técnica e econômica cega - imposta "de cima para baixo" - frequentemente negligencia as dificuldades e as demandas existentes para que sobretudo os pequenos produtores possam participar desta nova cadeia de valor e, assim, consigam alcançar melhores condições de vida.

\section{Considerações finais}

Tanto a produção como o consumo de produtos orgânicos vem aumentando, baseado em discursos que se contrapõem aos parâmetros de produção estabelecidos pela agricultura moderna (sobretudo a produção de commodities) e valorizando práticas agrícolas "ecologicamente corretas", relações sociais de produção mais equânimes, e propondo o fortalecimento da autonomia e identidade dos agricultores e regiões produtoras. Desse modo, a produção orgânica certificada vem representando um movimento de descomoditização da produção no campo, mesmo que seu alcance seja limitado e seus efeitos para o conjunto dos produtores rurais possam ser questionados.

A cacauicultura brasileira se inseriu neste movimento a partir do final dos anos 1990, após a chamada “crise do cacau". Desde então, observa-se o surgimento de uma nova dinâmica de especialização produtiva no Sul da Bahia - uma das principais regiões cacauicultoras do país - fenômeno este que ocorre através do desenvolvimento de sistemas especiais de produção de cacau, dentre os quais destaca-se a produção de cacau orgânico certificado. Em certa medida, trata-se de uma "atualização produtiva regional" que resulta de estratégias adotadas por instituições, produtores e empresas com a finalidade de (re)inserir o Sul Baiano nos modernos circuitos espaciais de produtos agrícolas.

Entretanto, em função da racionalização do processo de certificação e a primazia exercida pelas empresas certificadoras, grande parte dos cacauicultores do Sul Baiano tem dificuldades para participar dos novos e mais rentáveis circuitos espaciais de produtos certificados, devido as condições técnicas, financeiras e informacionais limitativas que 
dispõem. Por causa da racionalidade técnica e econômica estreita que orienta o processo de certificação dos agricultores, alguns dos princípios e objetivos fundamentais do movimento de certificação dos produtos orgânicos deixam então de ser contemplados, e novas formas de segregação e desigualdades entre os produtores passam a ser gestadas na tradicional região cacaueira da Bahia.

A Cooperativa Cabruca e Rede Povos da Mata, apesar de estarem inseridas no modelo de produção orgânica certificada, nos revelam lógicas e formas distintas de inserção dos produtores nesta nova cadeia de valor, visto que enquanto a primeira de certa forma se ajusta aos padrões técnicos e organizacionais próprios a uma racionalidade produtiva dominante que se estabelece também neste circuito, a segunda apoia-se num modelo mais horizontal de certificação da produção, que ao contrário de produzir segregação tende a possibilitar a incorporação dos pequenos produtores, através do modelo de certificação participativa.

A partir das análises da Cooperativa Cabruca e da Rede Povos da Mata, observamse formas e estratégias distintas de inserção dos diferentes grupos de produtores nos novos circuitos espaciais de produtos agrícolas certificados, as quais permitem-nos também observar lógicas e efeitos diferentes proporcionados pela nova dinâmica de especialização regional da produção de cacau no Sul Baiano.

A experiência da Cooperativa Cabruca sinaliza para uma adequação dos produtores a uma estrutura pragmática de controle e regulação da produção, no qual a racionalidade técnica e econômica da certificação por auditoria assume papel orientador das ações realizadas pela própria cooperativa. Por outro lado, a experiência da Rede Povos da Mata, ao nosso ver, apoia-se eminentemente numa "solidariedade local", visto que se ajusta as demandas, aos interesses e as possibilidades de atuação dos produtores locais nos novos circuitos espaciais de produtos agrícolas certificados, necessitando assim que essa experiência seja compreendida, sobretudo, como uma espécie de "revanche" dos pequenos produtores às limitações e obstáculos produzidos pelo atual modelo de produção agrícola certificada.

Finalmente, é possível também dizer que apesar das contradições produzidas pelo fenômeno de descomoditização da produção, pôde-se constatar que a produção agrícola certificada abre possibilidades de melhoria das condições de vida sobretudo para os pequenos produtores, os quais através da construção de articulações locais e da defesa de 
interesses e projetos comuns, conseguem se contrapor aos mercados agrícolas padronizados, passando a gozar de uma maior autonomia econômica e política, conquistadas através da valorização das formas especiais de produção que praticam.

\section{REFERÊNCIAS}

CABRUCA. Home page institucional. Disponível em:

$<$ https://www.cabruca.com.br/>. Vários acessos em Abril de 2020.

\section{CHIAPETTI, J. O uso corporativo do território brasileiro e os processos de} formação de um espaço derivado: Transformações e Permanências na Região Cacaueira da Bahia. Tese (Doutorado em Geografia) - Universidade Estadual Paulista, Rio Claro, 2009.

A crise da atividade cacaueira no contexto do reordenamento da economia mundial. Agrotrópica. Centro de Pesquisas do Cacau, Ilhéus. 26 (3), 2014, p. 165 174.

CHIAPETTI, J.; ROCHA, R.; CONCEIÇÃO, A. (Org.). Panorama da cacauicultura no território litoral sul da Bahia (2015-2019). Instituto Floresta Viva: Ilhéus, 2020.

COGUETO, J. V. Indicação Geográfica e cafés especiais: circuito espacial produtivo e círculos de cooperação dos cafés da Região da Serra da Mantiqueira de Minas Gerais. Dissertação (Mestrado em Geografia) - Universidade Estadual Paulista, Rio Claro, 2014.

CRUZ, B. E. V.; HESPANHOL, R. M. Indicação geográfica e queijos artesanais: marco legal e desafios a uma política para este segmento no Brasil. Confins, 37, 2018, p. 1-18.

DAVIRON, B; VAGNERON, I. From commoditization to de-commoditization ... and back again. Discussing the role of sustainability standards for agricultural.

Development Policy Review. 29 (1), 2011, p. 91-113.

FARRAN, K. A territorialização da Agroecologia na Bahia: uma análise a partir do Assentamento Dois Riachões (Movimento Ceta) e da Rede de Agroecologia Povos da Mata (2015-2018). Dissertação (Mestrado em Geografia). Universidade Federal da Bahia, Salvador, 2019.

FREDERICO, S. Lógicas das commodities, finanças e cafeicultura. Boletim Campineiro de Geografia. vol. 3 (1), 2013, p. 97 - 116.

FREDERICO, S; BARONE, M. Globalização e cafés especiais: a produção do comércio justo da Associação dos Agricultores Familiares do Córrego D’Antas ASSODANTAS, Poços de Caldas (MG). Sociedade \& Natureza, Uberlândia, 27 (3), set-dez/2015, p. 393-404. 
GOMES, A.; PIRES, M. (Orgs). Cacauicultura: estrutura produtiva, mercados e perspectivas. Ilhéus, BA: Editus, 2015.

IBGE. (Instituto Brasileiro de Geografia e Estatística). Sistema IBGE de Recuperacão Automática - SIDRA. Brasília, DF: IBGE, 2020. Disponível em:

<https://sidra.ibge.gov.br/tabela/1613\#resultado>. Vários acessos em Abril de 2020.

ICCO. (International Cocoa Organization). A Study on the Market for Organic Cocoa. Executive Committee. One hundred and thirtieth meeting, London, Sep./2006, p. 1215.

LOBÃO, D. E. Agroecossistema cacaueiro da Bahia: cacau-cabruca e fragmentos florestais na conservação de espécies arbóreas. Tese (Doutorado), Universidade Estadual Paulista, Jaboticabal, 2007.

MAPA (Ministério da Agricultura Pecuária e Abastecimento). Cadastro Nacional de Produtores Orgânicos. (Valido até 31/03/2020). Disponível em:

$<$ http://www.agricultura.gov.br/assuntos/sustentabilidade/organicos/cadastro-nacionalprodutores-organicos>. Acessado em: 17 de março de 2020.

MERCADO DO CACAU. IG Cacau Sul da Bahia destaca certificação de origem no Inova Cacau. Mercado Do Cacau. Publicada em 5/12/2019. Disponível em: $<$ http://mercadodocacau.com/artigo/ig-cacau-sul-da-bahia-destaca-certificacao-deorigem-no-inova-cacau>. Acessado em 14/04/2020.

NIEDERLE, P.; DELPHINE, V. Indicações Geográficas e qualificação no setor vitivinícola brasileiro. Estudos Sociedade e Agricultura, vol. 18, n. 1, abr/2010, p. 555.

NOIA, A; MIDLEJ, M.; ROMANO, J. A cacauicultura na região sul da Bahia: trajetória, crises e perspectivas. GOMES, A. PIRES, M. (Orgs). Cacauicultura: estrutura produtiva, mercados e perspectivas. Ilhéus, BA: Editus, 2015. p. 16-41.

POVOS DA MATA. Home page institucional. Disponível em: <http://povosdamata.org.br/>. Vários acessos em Abril de 2020.

PENTEADO, S. Certificação Agrícola: Selo Ambiental e Orgânico. Edição do Autor; Campinas-SP, 2010.

PIRES, M., et. al. Dinâmica e análise econômica da viabilidade dos sistemas de produção de cacau orgânico do sul da Bahia. GOMES, A. PIRES, M. (Orgs).

Cacauicultura: estrutura produtiva, mercados e perspectivas. Ilhéus, BA: Editus, 2015. p. 44-78.

REIS, L. C. Os artifícios do Estado para a reprodução do capital: o discurso do "comércio justo". Dissertação (Mestrado em Geografia). Universidade Federal de Sergipe, São Cristóvão, 2015. 
ROCHA, L. B. A região cacaueira da Bahia - dos coronéis à vassoura-de-bruxa: saga, percepção, representação. Ilhéus: Editus, 2008.

SANTOS, M. Da totalidade ao Lugar. São Paulo: Edusp, 2005.

SANTOS, A. M.; SANTOS, G. B.; SANTOS, P. B. Cacau fino: produção, consumo e tecnologia. GOMES, A. PIRES, M. (Orgs). Cacauicultura: estrutura produtiva, mercados e perspectivas. Ilhéus, BA: Editus, 2015. p. 229-254.

SEBRAE (Serviço Brasileiro de Apoio às Micro e Pequenas Empresas). Análise Estratégica Setorial - Cacau do Sul Da Bahia. Instituto Arapyaú. 2019. Disponível em: <https://arapyau.org.br/conteudo/publicacoes/page/2/>. Vários acessos: Março de 2020. 